\title{
Effects of surface treatments on the bond strength of glass hybrid restorative system repaired with hybrid composite resin
}

\author{
Banu Arıcıoğlu1 ${ }^{\oplus}$, Ömer Hatipoğlu² \\ ${ }^{1}$ Recep Tayyip University, Faculty of Dentistry, Department of Endodontics, Rize, Turkey \\ ${ }^{2}$ Kahramanmaraş Sütçü İmam University, Faculty of Dentistry, Department of Restoratif Dentistry, Kahramanmaraş, Turkey
}

\section{Correspondence:}

Dr. Ömer HATiPOĞLU

Kahramanmaraș Sütçü İmam University, Faculty of Dentistry, Department of Restoratif Dentistry, Kahramanmaraș, Turkey

E-mail:ohatipoglu@ksu.edu.tr

Received: 21 October 2018

Accepted: 30 November 2018

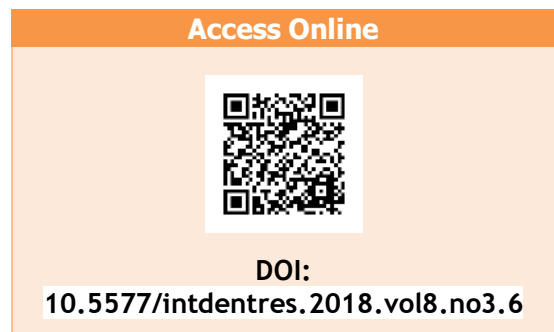

\section{Introduction}

Glass ionomer cement (GIC) is a commonly preferred material among in the restorative treatment of the teeth. Compared to the resin-based composites (RBCs), it has advantages of being able to bind to

\section{Abstract}

Aim: To assess the bonding strength of the Equia Forte resin-modified glass ionomer cement to the hybrid composite material by applying different surface treatments.

Methodology: 140 samples as 70 Equia Forte and $70 \mathrm{G}$-eanial composites were produced as $8 \mathrm{~mm}$ diameter $3 \mathrm{~mm}$ high cylindrical standardized samples. The samples were divided into 7 groups to treat surfaces. Geanial composite resins as $4 \mathrm{~mm}$ diameter $3 \mathrm{~mm}$ high was placed onto the samples and polymerized. Then 1000 thermal cycle was applied and samples were mounted in the universal testing machine. Obtained bond strength values were recorded as Newton. One way Anova and Scheffe post hoc tests were performed for statistics.

Results: In the G-aenial group, the highest bond strength was obtained with laser-bond method $(\mathrm{N}=17.71, \mathrm{P}<0.05)$ and the lowest bonding strength was obtained with only laser-treated method $(\mathrm{N}=3.45, \mathrm{P}<0.05)$. In the Equia group, the highest bond strength was obtained with air abrasionbond method $(\mathrm{N}=9.29, \mathrm{P}<0.05)$ and the lowest bonding strength was obtained with only laser-treated method $(n=0.00, p<0.05)$.

Conclusions: The fact that sufficient bond strength could not be reached by any surface treatment in Equia Forte may suggest that replacing the Equia Forte instead of repairs may be a better choice.

Keywords: Bond strength, repair, surface treatment

How to cite this article: Arıcıoğlu B, Hatipoğlu Ö. Effects of surface treatments on the bond strength of glass hybrid restorative system repaired with hybrid composite resin. Int Dent Res 2018;8(3):131-8. enamel and dentin chemically and to be anti-cariogenic since it can release long-term fluoride. In addition, it is preferred by clinicians due to it has excellent biological adaptation and a lower coefficient of thermal expansion (1-3). In addition, being low physical resistance and abrasion resistance, susceptible to 
moisture, and inadequate esthetic limit the use of it in the permanent teeth $(4,5)$.

With the developments in recent years, the physical strengths of GIC have increased. EQUIA Forte (GC, America) is a new GIC system that was released to the market in terms of it has high physical properties. It has been mentioned that this feature is provided by ultra-thin, highly reactive glass particles dispersed in a high molecular weight polyacrylic acid. While using conventional GIC is not indicated in classical permanent restorations, it was alleged that EQUIA can be used in permanent class 1 restorations and even in class 2 restorations which are not under high stress (1, 6).

Although permanent restorations, especially in recent years, may be able to withstand high mechanical stresses, PH changes (7), salivary enzymes (8), thermal changes (9) can weaken the mechanical properties of restorations and fractures can occur in restorations. Generally, broken restorations are either completely replaced by clinicians or parts of old restorations are partially removed and repaired with a new restoration. Complete removal of the broken restoration may cause more tooth material loss and damage to the pulp tissue (10). Clinicians may prefer to repair broken restorations in terms of reducing both economic and dental material loss (11).

The efficiency of the adhesive systems can be increased by modifying the structure of the restoration surface to be repaired with different methods. These methods are applied with the aim of increasing the surface energy of the restoration to be repaired and irregularizing the surface structure that increases surface area, removing the layer on the restoration surface which underwent structural change due to saliva effect (12). Traditionally as well as acid application to the tooth surface, new techniques such as laser application $(13,14)$, aluminium oxide abrasion $\left(\mathrm{Al}_{2} \mathrm{O}_{3}\right)(15-17)$ have become popular.

Although the effect of surface treatments on bond strength in the repair of the RBCs has been investigated many times, there is no study in the literature evaluating the bond strength of the Equia Forte resinmodified glass ionomer cement (RMGIC) to the RBC. The purpose of this study was to evaluate the bonding performance of the hybrid RBC to the Equia Forte RMGIC and the bonding performance of the hybrid RBC to the hybrid RBC. In addition, it was aimed to compare the bonding strengths each other.

\section{Materials and Methods}

The sample size was calculated by the statistical program GPower

3.0.10 (http://www.gpower.hhu.de/). The necessity of 126 samples with $80 \%$ power, 0.05 alpha error and 0.4 effect size was determined. Silicone mold was prepared to produce $8 \mathrm{~mm}$ diameter $3 \mathrm{~mm}$ high cylindrical standardized samples. The brands, manufacturers and chemical compositions of the materials used in this study are listed in Table 1. 140 samples as 70 RMGICs and 70 RBCs (GC, USA) were placed in this mold as a single layer. After placing the mylar strips in order to eliminate material gaps, restorative materials were compressed with a glass plate. Each restorative material was placed in the mold in a single step. After the excess of material had been eliminated, the RBCs were polymerized for 20 seconds at a maximum distance of $10 \mathrm{~mm}$ according to the manufacturer's instructions (VALO Cordless, Ultradent, South Jordan, Utah, USA; the power output of 1200 $\mathrm{mW} / \mathrm{cm}^{2}$ ). The samples of Equia Forte RMGIC were set according to manufacturer instruction (about 6 minutes).

RMGIC and RBC samples were divided into 7 groups $(n=10)$ for different surface treatments (Fig. 1).

- Group 1: No surface treatment was applied to the samples.

- Group 2: G-Premio Bond (GC, USA) was applied to the samples and polymerized with the LED light source (VALO Cordless, Ultradent, South Jordan, Utah, USA) for 10 seconds.

- Group 3: $37 \%$ phosphoric acid was applied to the samples for 15 seconds and the surface was washed for 15 seconds. After the surface was dried with cotton pellets, G-Premio Bond (GC, USA) was applied and polymerized for 10 seconds with the LED light source (VALO Cordless, Ultradent, South Jordan, Utah, USA).

- Group 4: $\mathrm{Al}_{2} \mathrm{O}_{3}$ with a size of $50-\mu \mathrm{m}$ under 60 PSI for 5 seconds was applied to the samples with an air abrasion device (AEROETCHER, D670, PARKELL Farmingdale, NY, USA).

- Group 5: After $\mathrm{Al}_{2} \mathrm{O}_{3}$ was applied to the samples as described in the group 4, G-Premio Bond (GC, USA) was applied to the samples and polymerized for 10 seconds with the LED light source (VALO Cordless, Ultradent, South Jordan, Utah, USA).

- Group 6: The Er: YAG laser (LightWalker; Fotona, Ljubljana, Slovenia) was applied at a power output of $10 \mathrm{~Hz}$ and a water output of $1.2 \mathrm{~W}$ under $5 \mathrm{ml}$ of water per minute. The HCO2-N handpiece was held parallel upon the restoration at a distance of $10 \mathrm{~mm}$. The size of the laser beam was $0.9 \mathrm{~mm}$. To standardize the distance, an acrylic block, previously prepared $10 \mathrm{~mm}$ long, was used.

IDR - Volume 8, Number 3, 2018 
- Group 7: After applying the laser as described in group 6, G-Premio Bond (GC, USA) was applied and polymerized for 10 seconds with the LED light source
(VALO Cordless, Ultradent, South Jordan, Utah, USA).

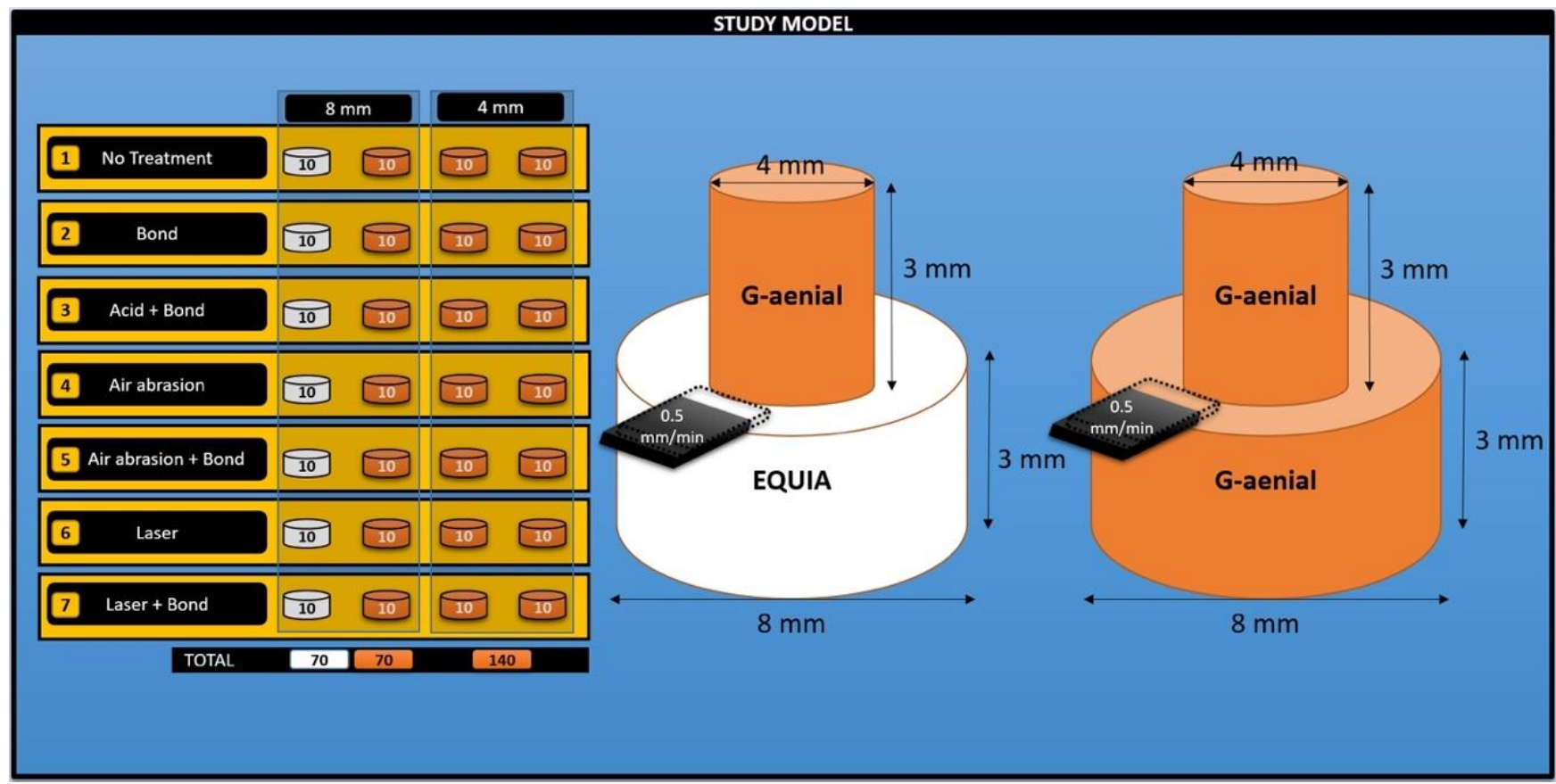

Figure 1. Procedure and study model followed in the study.

$4 \mathrm{~mm}$ diameter $3 \mathrm{~mm}$ high plastic matrixes were prepared and placed in the center of the surface. RBCs were placed in a single step and each was polymerized for 20 seconds. After bonding, RMGIC samples were coated with Equia Forte Coat (GC, USA) and photocured for 20 seconds using a LED light source (VALO Cordless, Ultradent, South Jordan, Utah, USA). Then, the prepared samples were placed in the thermal cycle device (Gokceler Makine, Sivas, Turkey) which was adjusted to the temperature between $5{ }^{\circ} \mathrm{C}$ and $55^{\circ} \mathrm{C}$. The duration of each immersion in the bath was determined to be 30 seconds and 1000 thermal cycles were applied. The samples taken from the thermal cycle device were mounted on a universal testing machine (Instron 3340, Wycombe, UK) to measure the shear bond strength. In order to be mounted on the test device, the samples were buried in the acrylic moulds. The samples were fixed to the bottom part of the device. The V-shaped metal bar was positioned in the upper part of the test device in parallel with the interface of the restorations. The shear forces applied to the full of the contact area at a cross-head speed of $0.5 / \mathrm{min}$. The shear forces were continued until the connection between the restorations breakaway. The bond strength value was recorded as Newton (N) for each sample and the results were converted to $\mathrm{MPa}$ using the formula $F=N / A$ ( $N$ : Newton, A: surface area).
The fracture surfaces were examined with a stereomicroscope (Stemi 305, Carl Zeiss Microscopy $\mathrm{GmbH}$, Göttingen, Germany) at $30 \times$ magnification to determine the fracture types after the bonding strength test of all samples. Fracture types were assessed as an adhesive failure if it occurred in adhesive bonding or cohesive failure if it occurred in restoration, or mixed failure if it involves both restoration and adhesive bonding.

Data analysis was performed using the Statistical Package for the Social Sciences version 23.0 (SPSS Inc., Chicago, Il., USA). One way Anova and Scheffe post hoc tests were performed. $P$ value $<0.05$ was considered as statistically significant. Spontaneous debondings in the thermal cycle process were considered as $0 \mathrm{MPa}$.

\section{Statistical Analysis}

Data analysis was performed using the Statistical Package for the Social Sciences version 23.0 (SPSS Inc., Chicago, Il., USA). One way Anova and Scheffe post hoc tests were performed. $P$ value $<0.05$ was considered as statistically significant. Spontaneous debondings in the thermal cycle process were considered as $0 \mathrm{MPa}$. 


\section{Results}

The highest bond strength in the $\mathrm{G}$-aenial group was obtained with laser-bond method $(\mathrm{N}=17.71$, $\mathrm{P}<0.05)$ and the lowest bond strength was in the only laser-treated group $(\mathrm{N}=3.45, \mathrm{P}<0.05)$. Groups only treated with bond and only treated with air abrasion showed similar bond strength values $(P>0.05)$. There was a significant difference between the other surface treatment methods $(P<0.05)$. The highest bond strength in the Equia group was obtained with air abrasion-bond method $(\mathrm{N}=9.29, \mathrm{P}<0.05)$ and the lowest bonding strength was only in the laser treated group
$(\mathrm{N}=0.00, \mathrm{P}<0.05)$. Groups only treated with bond, only treated with laser, only treated with air abrasion, and the control group showed similar bond strength values $(P>0.05)$. There was a significant difference between the other surface treatment methods $(P<0.05)$. The bond strength in the $\mathrm{G}$-aenial group was significantly higher than the bond strength in the Equia group in all surface treatments $(\mathrm{P}<0.05)$ (Table 2$) .24$ samples (17.14\%) failed before the bond strength test, most of them were in the Equia groups which only treated with the laser (Table 2). When examined the fracture modes, adhesive, cohesive, and mixed failures were observed $60 \%, 16 \%, 24 \%$ for Equia and $65 \%, 14 \%, 21 \%$ for G-eanial composite, respectively (Table 3 ).

Table 1. Materials used in the study.

\begin{tabular}{|c|c|c|c|}
\hline Materials & Manufacturer & Lot Code(s) & Chemical Composition \\
\hline Scotchbond Etchant Gel & $\begin{array}{l}\text { 3M Dental Products, } \\
\text { St. Paul, MN, USA }\end{array}$ & $8 U 0031$ & \%37 phosphoric acid \\
\hline $\begin{array}{l}\text { Equia Forte bulk fill glass } \\
\text { hybrid restorative system }\end{array}$ & GC, USA & 1608271 & Glass particles, polyacrylic acid \\
\hline $\begin{array}{l}\text { G-eanial Posterior light- } \\
\text { cured radiopaque hybrid } \\
\text { composite (Shade } \mathrm{A} 2 \text { ) }\end{array}$ & GC, USA & 1711271 & $\begin{array}{l}\text { Urethane dimethacrylate (UDMA), } \\
\text { dimethacrylate co-monomers, Silica, } \\
\text { Strontium and Lanthanoid Fluoride, } \\
\text { Fluoroaluminosilicate, Fumed silica }\end{array}$ \\
\hline G-Premio Bond & GC, USA & 1712021 & $\begin{array}{l}\text { 10-MDP, phosphoric acid ester } \\
\text { monomer, dimethacrylate, } \\
\text { 4-MET, MEPS, acetone, silicon } \\
\text { dioxide, initiators }\end{array}$ \\
\hline Equia Forte Coat & GC, USA & 1504201 & $\begin{array}{l}50 \% \text { methyl methacrylate, } 0.09 \% \\
\text { camphorquinone }\end{array}$ \\
\hline
\end{tabular}

Table 2. Mean micro-shear bond strengths (standard deviations)

\begin{tabular}{lllll}
\hline Method & \multicolumn{1}{l}{ G-aenial + G-aenial } & & Equia + G-aenial \\
& Mean Values (SD) & PTF & Mean Values (SD) & PTF \\
\hline Control & $6.25(0.48) \mathrm{d}$ & 1 & $0.89(0.4) \mathrm{a}$ & 3 \\
\hline Bond & $12.22(1.28) \mathrm{h}$ & - & $1.84(0.73) \mathrm{a}, \mathrm{b}$ & 3 \\
\hline Acid + Bond & $8.35(1.42) \mathrm{e}, \mathrm{f}$ & - & $4.11(1.21) \mathrm{c}$ & - \\
\hline Air abrasion & $11.28(0.96) \mathrm{g}, \mathrm{h}$ & - & $1.87(0.31) \mathrm{a}, \mathrm{b}$ & - \\
\hline Air abrasion + Bond & $15.28(1.61) \mathrm{i}$ & - & $9.29(0.88) \mathrm{f}, \mathrm{g}$ & 10 \\
\hline Laser & $3.45(0.48) \mathrm{b}, \mathrm{c}$ & 3 & $0.00(0.00) \mathrm{a}$ & - \\
\hline Laser + Bond & $17.71(1.15) \mathrm{j}$ & - & $7.07(0.99) \mathrm{d}, \mathrm{e}$
\end{tabular}

Different letters indicate significant differences between the groups $(\mathrm{p}<0.05)$. PTF: Pre-test failure. 
Table 3. Frequency of modes of failure in Equia and G-aenial composite.

\begin{tabular}{|c|c|c|c|c|}
\hline \multirow[t]{2}{*}{ Study Groups } & \multirow{2}{*}{$\begin{array}{l}\text { Substrate } \\
\text { specimens }\end{array}$} & \multicolumn{3}{|c|}{ Fracture Modes } \\
\hline & & Adhesive & Cohesive & Mixed \\
\hline \multirow{2}{*}{ Control } & Equia & 5 & 1 & 1 \\
\hline & G-aenial & 7 & 1 & 1 \\
\hline \multirow{2}{*}{ Bond } & Equia & 7 & 0 & 0 \\
\hline & G-aenial & 7 & 2 & 1 \\
\hline \multirow{2}{*}{ Acid + Bond } & Equia & 8 & 0 & 2 \\
\hline & G-aenial & 7 & 1 & 2 \\
\hline \multirow{2}{*}{ Air abrasion } & Equia & 6 & 0 & 0 \\
\hline & G-aenial & 5 & 3 & 2 \\
\hline \multirow{2}{*}{ Air abrasion + Bond } & Equia & 5 & 3 & 2 \\
\hline & G-aenial & 6 & 0 & 4 \\
\hline \multirow{2}{*}{ Laser } & Equia & 2 & 0 & 0 \\
\hline & G-aenial & 4 & 1 & 2 \\
\hline \multirow{2}{*}{ Laser + Bond } & Equia & 5 & 4 & 1 \\
\hline & G-aenial & 7 & 1 & 2 \\
\hline
\end{tabular}

\section{Discussion}

GIC has advantages such as chemical bonding, fluoride release and anti-cariogenic properties, but their usage is restricted due to their poor mechanical properties. Along with the developments in recent years, GIC containing nano-sized glass particles and highly branched polyacrylic acid products in high molecular weight have been released to the market (18). These evolving properties of GIC have also allowed them to be used in permanent restorations (6).

Previous studies have suggested that repairing defective restorations rather than total replacing can prolong the life of the restoration $(19,20)$. Because the total replacement of a defective restoration may cause more damage to the healthy dental tissue and occur damage to the pulp tissue (21). Because GIC is more brittle and less resistant to abrasion forces, they may need to be repaired or replaced more often than RBCs (22).

Microorganisms, constituents of beverages and foods, $\mathrm{pH}$ changes, salivary enzymes, and thermal changes can degrade dental materials chemically and mechanically (20). The manufacturer recommends the application of resin coating to prevent damage to the Equia Forte RMGIC from moisture and changing temperature. However, application of resin coating to the RMGIC surface, which is used as a base under the $\mathrm{RBC}$ or will be repaired with the RBC after it is broken, will reduce the bonding strength (6). In this study, we did not apply resin coating before bonding, because we desired to examine the bonding strength of the broken RMGIC to the RBC.

One of the methods used to simulate the ageing process of dental materials is thermocycling. It is predicted that 10000 thermal cycles are equivalent to about 1 year in vivo function (23). In our study, the thermal cycle process was applied after the bonding with the aim of imitating the oral environment. However, in many studies, it has been shown that the thermocycling procedure reduces the bonding strength by a significant amount (16). Stallings, et al. (22) noted that when the coating is not applied, the bonding strength of the Equia system will be reduced. So that, we applied the coating agent to Equia samples after bonding, prior to beginning thermocycling process.

In this study, $\mathrm{Al}_{2} \mathrm{O}_{3}$ increased the bonding strength significantly in the repair process of the RBCs. Most of the previous studies have also found that $\mathrm{Al}_{2} \mathrm{O}_{3}$ increases the bond strength significantly $(16,24-32)$, but a few studies found that opposite results $(33,34)$. $\mathrm{Al}_{2} \mathrm{O}_{3}$ has the ability to form micro retention areas and these areas increase wettability and adhesion to the restoration (35). The adhesive penetrates the microretention areas on the surface of restoration and provides a strong mechanical bonding after polymerization (36). In Equia Forte, sufficient bond strength not obtained when the bonding agent was not 
added to $\mathrm{Al}_{2} \mathrm{O}_{3}$ application. This situation can be explained by the fact that the RMGIC system does not contain the adequate monomeric structure and, as a consequence, not occurred sufficient bonding forces at the GIC-composite interface without bonding agent.

The reason for using the adhesive resin in the RBC repairs is to increase the surface wettability by penetrating the resin into the micromechanical areas which were formed by surface treatments (37). GPremio Bond is a self-etch adhesive system which was recommended for direct bonding, repair, and hypersensitive treatments (38). Staxrud, et al. found that stronger bonding strengths occurred in the RBCs repaired using adhesives (11). In this study, the bonding agent application increased the bonding strength of the repairment significantly (either RBC or RMGIC) after all surface treatments. However, especially for Equia Forte, the application of adhesives seems to be an indispensable requirement since it was acquired very low bonding strengths in all samples which were not applied adhesive.

Phosphoric acid etching is one of the preferred routine applications in the repair of restorations. It is especially applied to the dental tissue adjacent restoration so that sufficient bonding strengths can be obtained. There are conflicting results between the studies in terms of contribution to bond strength. Although some studies indicated that they increase (39) or decrease $(36,40)$ bonding strength, some studies have not found any significant effect $(26,41)$. In the present study, while acid treatment with the bonding agent decreased the bonding strength between the composites, it improved the bonding strength between the RMGIC and the RBC.

Adhesive failures were obtained mostly in the present study, may be due to insufficient bonding strength between restorations. It is considered that the minimum required bond strength must be between 17 $20 \mathrm{MPa}$ to obtain adequate resistance to shrinkage forces and to achieve gap-free restoration margins (42). Neither the G-aenial RBC nor the Equia Forte RMGIC were the substrate material required to achieve adequate bond strength, except laser+bond application to G-aenial RBC.

When Er: YAG laser was applied to the surface of the RBC, explosive vaporization and hydrodynamic ejection processes occur to accomplish ablation. In these processes, rapid melting and changes in the volume of the material occur. Emerged strong expansion forces cause projections on the surface of the RBC and the molten material is discharged from the surface in the form of droplets $(43,44)$. The resulting micro retentive areas expand the surface area of the RBCs and thus increase the bonding surface which will increase the bond strength after repair. Oskoee, et al. (45) stated that the Er-YAG laser increases the bonding strength more than other lasers. In some studies, it has been found that $\mathrm{Al}_{2} \mathrm{O}_{3}$ and $\mathrm{Er}$-YAG lasers occur similar bonding strength $(46,47)$, whereas some studies have shown that Er-YAG laser is superior $(48,49)$. In the present study, Er-YAG laser when applied with the adhesive was the application which increased the bonding strength of the RBC most significantly, whereas $\mathrm{Al}_{2} \mathrm{O}_{3}$ applied with the adhesive increased the bonding strength of Equia Forte RMGIC most significantly. When no adhesive was applied, the laser application caused very low bonding strength, and even, all samples of Equia Forte RMGIC failed before the test.

\section{Conclusions}

When adhesive was not applied, very low bonding strengths were obtained in all surface treatments. This means that the application of adhesives has a critical role on bonding strength, especially for Equia Forte RMGIC. Er-YAG laser produced the strongest bond strength when applied with adhesive in G-aenial composite, but in Equia Forte RMGIC, the strongest bond strength was achieved using air abrasion. The fact that adequate bond strength could not be achieved by any surface treatment in Equia Forte RMGIC may suggest that replacing the Equia Forte RMGIC instead of repairs may be a better option.

Peer-review: Externally peer-reviewed.

Author Contributions: Conception - B.A.; Design - Ö.H.; Supervision - B.A.; Materials - Ö.H.; Data Collection and/or Processing - B.A.., Ö.H.; Analysis and/or Interpretation - Ö.H.; Literature Review - Ö.H.; Writer - B.A., Ö.H.; Critical Review - Ö.H.

Conflict of Interest: No conflict of interest was declared by the authors.

Financial Disclosure: The authors declared that this study has received no financial support. 


\section{References}

1. Wiegand $\mathrm{A}$, Attin $\mathrm{T}$. Influence of fluoride on the prevention of erosive lesions--a review. Oral Health Prev Dent 2003;1:245-53.

2. Sidhu SK. Clinical evaluations of resin-modified glass-ionomer restorations. dental materials 2010;26:7-12. (Crossref)

3. Glasspoole EA, Erickson RL, Davidson CL. Effect of surface treatments on the bond strength of glass ionomers to enamel. Dental materials 2002;18:454-62. (Crossref)

4. Sidhu S. Glass-ionomer cement restorative materials: a sticky subject? Australian dental journal 2011;56:23-30. (Crossref)

5. Manhart J, Chen H, Hamm G, Hickel R. Review of the clinical survival of direct and indirect restorations in posterior teeth of the permanent dentition. Operative Dentistry 2004;29:481508.

6. GC-EUROPE (2018) EQUIA Forte Bulk fill glass hybrid restorative system. https://www.gceurope.com/products/equiaforte/. Accessed 2018.

7. Bagheri R, Tyas M, Burrow M. Subsurface degradation of resinbased composites. Australian Dental Journal 2006;51:S6.

8. Jaffer $F$, Finer $Y$, Santerre J. Interactions between resin monomers and commercial composite resins with human saliva derived esterases. Biomaterials 2002;23:1707-19. (Crossref)

9. Mair L. Surface permeability and degradation of dental composites resulting from oral temperature changes. Dental Materials 1989;5:247-55. (Crossref)

10. Krejci I, Lieber CM, Lutz F. Time required to remove totally bonded tooth-colored posterior restorations and related tooth substance loss. Dental Materials 1995;11:34-40. (Crossref)

11. Staxrud F, Tveit A, Rukke H, Kopperud S. Repair of defective composite restorations. A questionnaire study among dentists in the Public Dental Service in Norway. Journal of dentistry 2016;52:50-4. (Crossref)

12. Hannig $C$, Laubach $S$, Hahn $P$, Attin $T$. Shear bond strength of repaired adhesive filling materials using different repair procedures. Journal of Adhesive Dentistry 2006; 8.

13. Delfino CS, Souza-Zaroni WC, Corona SAM, Palma-Dibb RG. Microtensile bond strength of composite resin to human enamel prepared using erbium: yttrium aluminum garnet laser. Journal of Biomedical Materials Research Part A 2007;80:475-9. (Crossref)

14. Souza-Zaroni WC, Chinelatti MA, Delfino CS, Pécora JD, PalmaDibb RG, Corona SA. Adhesion of a self-etching system to dental substrate prepared by Er: YAG laser or air abrasion. Journal of Biomedical Materials Research Part B: Applied Biomaterials 2008;86:321-9. (Crossref)

15. Malmström H, Chaves $\mathrm{Y}$, Moss M. Patient preference: conventional rotary handpieces or air abrasion for cavity preparation. Operative dentistry 2003;28:667-71.

16. Souza MO, Leitune VC, Rodrigues SB, Samuel SM, Collares FM. One-year aging effects on microtensile bond strengths of composite and repairs with different surface treatments. Braz Oral Res 2017;31:e4. (Crossref)

17. Fornazari IA, Wille I, Meda EM, Brum RT, Souza EM. Effect of Surface Treatment, Silane, and Universal Adhesive on Microshear Bond Strength of Nanofilled Composite Repairs. Oper Dent 2017;42:367-74. (Crossref)

18. Zhao J, Xie D. A novel hyperbranched poly (acrylic acid) for improved resin-modified glass-ionomer restoratives. dental materials 2011;27:478-86. (Crossref)

19. Fernandez E, Martin J, Vildosola P, Oliveira Junior OB, Gordan $\mathrm{V}$, Mjor I, et al. Can repair increase the longevity of composite resins? Results of a 10-year clinical trial. J Dent 2015;43:27986. (Crossref)

20. Opdam N, Van de Sande F, Bronkhorst E, Cenci M, Bottenberg $P$, Pallesen $U$, et al. Longevity of posterior composite restorations: a systematic review and meta-analysis. Journal of dental research 2014;93:943-9. (Crossref)

21. Demarco FF, Corrêa MB, Cenci MS, Moraes RR, Opdam NJ. Longevity of posterior composite restorations: not only a matter of materials. Dental Materials 2012;28:87-101. (Crossref)

22. Stallings MT, Stoeckel DC, Rawson KG, Welch DB. Significant shear bond strength improvements of a resin-modified glass ionomer cement with a resin coating. Gen Dent 2017; 65: 75-8.

23. Gale M, Darvell B. Thermal cycling procedures for laboratory testing of dental restorations. Journal of dentistry 1999; 27: 89-99. (Crossref)

24. Papacchini F, Magni E, Radovic I, Mazzitelli C, Monticelli F, Goracci C, et al. Effect of intermediate agents and pre-heating of repairing resin on composite-repair bonds. Operative dentistry 2007;32:363-71. (Crossref)

25. Costa T, Ferreira S, Klein-Júnior C, Loguercio A, Reis A. Durability of surface treatments and intermediate agents used for repair of a polished composite. Operative dentistry 2010;35:231-7. (Crossref)

26. Özcan M, Barbosa SH, Melo RM, Galhano GAP, Bottino MA. Effect of surface conditioning methods on the microtensile bond strength of resin composite to composite after aging conditions. Dental Materials 2007;23:1276-82. (Crossref)

27. Souza EM, Francischone CE, Powers JM, Rached RN, Vieira S. Effect of different surface treatments on the repair bond strength of indirect composites. American journal of dentistry 2008;21:93.

28. Frankenberger R, Krämer N, Ebert J, Lohbauer U, Käppel S, Petschelt A. Fatigue behavior of the resin-resin bond of partially replaced resin-based composite restorations. American journal of dentistry 2003;16:17-22.

29. Özcan M, Alander P, Vallittu P, Huysmans M-C, Kalk W. Effect of three surface conditioning methods to improve bond strength of particulate filler resin composites. Journal of Materials Science: Materials in Medicine 2005;16:21-7. (Crossref)

30. Junior SAR, Ferracane JL, Della Bona Á. Influence of surface treatments on the bond strength of repaired resin composite restorative materials. Dental Materials 2009;25:442-51. (Crossref)

31. Loomans B, Mesko M, Moraes R, Ruben J, Bronkhorst E, PereiraCenci T, et al. Effect of different surface treatment techniques on the repair strength of indirect composites. Journal of dentistry 2017;59:18-25. (Crossref)

32. Fornazari I, Wille I, Meda E, Brum R, Souza E. Effect of surface treatment, silane, and universal adhesive on microshear bond strength of nanofilled composite repairs. Operative dentistry 2017;42:367-74. (Crossref)

33. Hasan NH. The Influence of Er: YAG Laser, Alumi-num oxide and diamond bur on surface treatment of Aged Composite Resin to Repair Restoration. Al-Rafidain Dental Journal 2012:257-65.

34. Pounder B, Gregory W, Powers J. Bond strengths of repaired composite resins. Operative dentistry 1987;12:127.

35. Oztas N, Alacam A, Bardakcy Y. The effect of air abrasion with two new bonding agents on composite repair. Operative Dentistry 2003;28:149-54.

36. Lucena-Martín C, González-López S, de Mondelo JMN-R. The effect of various surface treatments and bonding agents on the repaired strength of heat-treated composites. The Journal of prosthetic dentistry 2001;86:481-8. (Crossref)

37. Rinastiti M, Özcan M, Siswomihardjo W, Busscher HJ. Effects of surface conditioning on repair bond strengths of non-aged and aged microhybrid, nanohybrid, and nanofilled composite resins. Clinical oral investigations 2011;15:625-33. (Crossref)

38. GC-EUROPE (2018) G-Premio BOND (One-component lightcured universal adhesive). https://www.gceurope.com/products/gpremiobond/. Accessed 2018. 
39. Wendler M, Belli R, Panzer R, Skibbe D, Petschelt A, Lohbauer U. Repair Bond Strength of Aged Resin Composite after Different Surface and Bonding Treatments. Materials (Basel) 2016;9. (Crossref)

40. Fawzy AS, El-Askary FS, Amer MA. Effect of surface treatments on the tensile bond strength of repaired water-aged anterior restorative micro-fine hybrid resin composite. Journal of dentistry 2008;36:969-76. (Crossref)

41. Lima AF, Ferreira SFA, Catelan A, Palialol ARM, Gonçalves LS, Aguiar FHB, et al. The effect of surface treatment and bonding procedures on the bond strength of silorane composite repairs. Acta Odontologica Scandinavica 2014;72:71-5. (Crossref)

42. Davidson C, De Gee A, Feilzer A. The competition between the composite-dentin bond strength and the polymerization contraction stress. Journal of dental research 1984;63:1396-9. (Crossref)

43. Correa-Afonso AM, Palma-Dibb RG, Pécora JD. Composite filling removal with erbium: yttrium-aluminum-garnet laser: morphological analyses. Lasers in medical science 2010;25:1. (Crossref)

44. Lizarelli RdF, Moriyama LT, Bagnato VS. Ablation of composite resins using Er: YAG laser-comparison with enamel and dentin. Lasers in Surgery and Medicine: The Official Journal of the American Society for Laser Medicine and Surgery 2003;33:1329. (Crossref)
45. Oskoee PA, Mohammadi N, Chaharom MEE, Kimyai S, Azar FP, Rikhtegaran S, et al. Effect of surface treatment with $\mathrm{Er}$; Cr: YSSG, Nd: YAG, and $\mathrm{CO} 2$ lasers on repair shear bond strength of a silorane-based composite resin. Journal of dental research, dental clinics, dental prospects 2013;7:61.

46. Ahmadizenouz G, Esmaeili B, Taghvaei A, Jamali Z, Jafari T, Amiri Daneshvar F, et al. Effect of different surface treatments on the shear bond strength of nanofilled composite repairs. J Dent Res Dent Clin Dent Prospects 2016;10:9-16. (Crossref)

47. Rossato D, Bandeca MC, Saade E, Lizarelli R, Bagnato VS, Saad JRC. Influence of Er: YAG laser on surface treatment of aged composite resin to repair restoration. Laser Physics 2009;19:2144. (Crossref)

48. Hasan S, Danishuddin M, Adil M, Singh K, Verma PK, Khan AU. Efficacy of $E$. officinalis on the cariogenic properties of Streptococcus mutans: a novel and alternative approach to suppress quorum-sensing mechanism. PLoS One 2012;7:e40319. (Crossref)

49. Alizadeh Oskoee P, Savadi Oskoee S, Rikhtegaran S, PournaghiAzar F, Gholizadeh S, Aleyasin Y, et al. Effect of Various Laser Surface Treatments on Repair Shear Bond Strength of Aged Silorane-Based Composite. J Lasers Med Sci 2017;8:186-90. (Crossref) 